\begin{tabular}{|c|l|}
\hline Title & $\begin{array}{l}\text { Dayside ionospheric uplift during strong geomagnetic storms as detected by the CHA MP, SA C-C, TOPEX and Jason-1 } \\
\text { satellites }\end{array}$ \\
\hline Author(s) & A stafyeva, Elviral. \\
\hline Citation & $\begin{array}{l}\text { Advances in Space Research, 43(11), 1749-1756 } \\
\text { https://doi.org/10.1016/.asr.2008.09.036 }\end{array}$ \\
\hline Issue Date & 2009-06-02 \\
\hline Doc URL & http://hdl.handle.net/2115/38845 \\
\hline Type & article (author version) \\
\hline File Information & 43-11_p1749-1756.pdf \\
\hline
\end{tabular}

Instructions for use 


\title{
Ionosphere redistribution during strong geomagnetic storms as detected by the CHAMP, SAC-C, TOPEX and Jason-1 satellites
}

\author{
Elvira I. Astafyeva* \\ Department of Natural History sciences, Hokkaido University, Kita-ku, N10 W8, Sapporo, 060-0810, \\ Japan,e-mail: elliada@mail.sci.hokudai.ac.jp \\ ${ }^{*}$ currently on leave from \\ Institute of Solar-Terrestrial Physics SB RAS, 126 Lermontov street, PO Box 291, Irkutsk, 664033, \\ Russian Federation
}

Ionosphere response to severe geomagnetic storms that occurred in 2001-2003 was analyzed using data of global ionosphere maps (GIM), altimeter data from the Jason-1 and TOPEX satellites, and data of GPS receivers onboard CHAMP and SAC-C satellites. This allowed us to study in detail ionosphere redistribution due to geomagnetic storms, dayside ionospheric uplift and overall dayside TEC increase. It is shown that after the interplanetary magnetic field turns southward and intensifies, the crests of the equatorial ionization anomaly (EIA) travel poleward and the TEC value within the EIA area increases significantly (up to 50\%). GPS data from the SAC-C satellite show that during the main phase of geomagnetic storms TEC values above the altitude of $715 \mathrm{~km}$ are 2-3 times higher than during undisturbed conditions. These effects of dayside ionospheric uplift occur owing to the «super-fountain effect» and last few hours while the enhanced interplanetary electric field impinged on the magnetopause.

\section{Introduction}

The ionosphere response to geomagnetic storms has been a subject of numerous studies for several decades (Abdu et al., 1991; Foster and Rideout, 2005; Huang et al., 2005; Mannucci et al., 2005; Zhao et al., 2005; Astafyeva et al., 2007; Basu et al., 2007). Ionospheric effects are known to be wide-ranging in their manifestations. One of the most outstanding modifications is alterations in ionospheric total electron content at equatorial and middle latitudes. The equatorial ionosphere represents perhaps the most persistent manifestation of ionosphere-thermosphere coupling at equatorial latitudes and serves as an indicator of the electric coupling status in the solar wind-magnetosphere-ionosphere system.

The equatorial plasma distribution is controlled by the neutral winds and electric fields. The neutral winds induce the hemispheric asymmetry of the ionosphere with respect to the magnetic equator, with large plasma flow (toward the hemisphere of stronger poleward wind) and a stronger anomaly crest occurring in opposite hemispheres. The electric field or the $\mathbf{E x B}$ drift creates the ionization trough at the magnetic equator and plasma density enhancements, EIA, at $\pm 12-15^{\circ}$ magnetic latitudes during geomagnetically quiet conditions (Abdu et al., 1990; Fejer, 1991; Balan and Bailey, 1995).

During the main phase of geomagnetic storms, when the interplanetary magnetic field (IMF) turns southward and intensifies, the interplanetary electric field can penetrate to the low-latitude ionosphere for many hours without decay (Gonzalez and Tsurutani, 1987; Gonzalez et al., 1994; Huang et al., 2005). The interconnection between southward IMF and the Earth's magnetic field leads to a strong dawn-to-dusk electric field which moves the equatorial F-region plasma upward enhancing the fountain effect: the fountain rises up to 800-1000 $\mathrm{km}$ altitude at the equator and covers about $\pm 30^{\circ}$ magnetic latitude. Solar photoionization replaces the uplifted plasma at lower altitudes, leading to an overall increase in ionosphere TEC (e.g., Vlasov et al., 2003; Tsurutani et al., 2004; Mannucci et al., 2005; Astafyeva et al., 2007; Basu et al., 2007). The phenomenon of the ionosphere dayside uplift due to "super fountain effect" (SFE) has been described and shown in detail for the geomagnetic storm on 5-6 November 2001 (Tsurutani et al., 2004). Then, the dayside SFE was observed during the "Halloween storms" of October 2003 (Mannucci et al., 2005, Basu et al., 2007; Tsurutani et al., 2007, 2008). In this paper we will present observations of the ionosphere dayside uplift due to the SFE during strong geomagnetic storms on 21-22 October 2001, 7-8 September 2002, 20-21 November 2003, using TEC 
measurements of the satellite altimeters TOPEX and Jason-1, CHAMP and SAC-C GPS data, as well as data of vertical TEC from global ionosphere maps.

\section{Methods of data analyses}

Figure 1 illustrates the scheme of the TEC measurements. For this analysis, simultaneous observations of TEC by the CHAMP, SAC-C, TOPEX/Jason-1 satellites were combined with the modeled global ionospheric maps (GIM) produced by the different IGS modeling centers. Each of these is described in more detail.

\subsection{Global Ionosphere Maps (GIM)}

Global ionosphere maps are generated using data from about 150 GPS sites of the IGS and other institutions. The vertical total electron content (VTEC) is modeled in a solar-geomagnetic reference frame, the technology of VTEC reconstruction was described in detail by Schaer et al. (1998) and Mannucci et al. (1998). The output files contain values of VTEC with spatial resolution of $2.5^{\circ}$ of latitude and $5^{\circ}$ of longitude, and a time resolution of 2 hours. In this paper we used data of CODE (http://www.aiub.unibe.ch/ionosphere.html) and by Jet Propulsion Laboratory of California Institute of Technology (JPL, http://www.jpl.nasa.gov/).

\subsection{Satellite altimeters TOPEX/Jason-1}

The dual-frequency satellite altimeters TOPEX and Jason-1 perform 1-sec measurements of VTEC beneath the satellites, i.e. between the water surface and the orbit height of about of $1335 \mathrm{~km}$ (Fu et al., 1994; http://www.aviso.oceanobs.com/html/missions/welcome uk.html). The orbit parameters are presented in Figure 1. The TOPEX/Poseidon satellite was launched on 10 August 1992 into a circular orbit at about $1300 \mathrm{~km}$ with an inclination $66.5^{\circ}$, an orbital period of 112 minutes and a repeat cycle of 10 days. Jason- 1 is a follow-on mission of the TOPEX/Poseidon mission; it was launched on 7 December 2001. The Jason-1 satellite flies the same ground-track as TOPEX.

Satellite altimeter observations of ice and sea surface heights are affected by the retardation/refraction of the altimeter signal in the ionospheric plasma. By measuring the heights above the Earth surface at two frequencies the ionosphere electron content between the ground and the satellite can be determined. Thus, dual-frequency altimeters provide TEC measurements as a byproduct of the sea surface height observations.

The data of satellite altimeters are very helpful in making observations in areas that lack ground-based instruments for observing the ionosphere, e.g., above oceans (Bilitza et al., 1996). However, since the altimeters were designed to measure only ocean heights, there are data gaps over landmasses.

To analyze the ionosphere response to geomagnetic storms on 21-22 October 2001 and on 20-21 November 2003 we used data of TOPEX altimeter and we used data of Jason-1 for geomagnetic storm on 7-8 September 2002.

\subsection{CHAMP data}

CHAMP is a project of the Potsdam Geophysical Observatory GFZ (http://op.gfz-potsdam.de/champ). CHAMP has a polar orbit ( $87^{\circ}$ inclination) and its orbital period is about 91 min (Figure 1). The orbit altitude changed from $\sim 450 \mathrm{~km}$ in 2001 to $350 \mathrm{~km}$ in 2005; thus, CHAMP passes are close to the height of the F2 layer peak density in a meridional direction allowing us to estimate the contribution of the upper ionosphere to TEC.

From the whole set of CHAMP TEC measurements we selected data those GPS satellites that had the maximum elevation angles at the time of observations. The disadvantage of this method is that TEC value may change by jumps at the points of changing a satellite with the maximum elevation angle. However, such approach provides reliable information about changes of the vertical TEC. The method of TEC retrieval from the data of on-board GPS receivers was described by Afraimovich et al. (2005)

\subsection{SAC-C data}


SAC-C is a joint project of the USA, Argentina, Brazil, Denmark, Italy and France (http://www.gsfc.nasa.gov/gsfc/service/gallery/fact sheets/spacesci/sac-c.html). The altitude of SAC-C satellite orbit is $715 \mathrm{~km}$ (Figure 1), so data from SAC-C allow us to estimate TEC within the range of latitudes from 715 $\mathrm{km}$ to $20,200 \mathrm{~km}$. The SAC-C data were selected and processed in a manner similar to that of CHAMP.

\section{Observations}

\subsection{Storm of 21-22 October 2001}

Fig. 2a shows variations of the index of geomagnetic activity Dst and of IMF $B_{z}$ on 21-22 October. The $B_{z}$ sharply turns southward and attains its maximum negative value of $-16.4 \mathrm{nT}$ at $18 \mathrm{UT}$. Then, the Dst value went sharply down from $17 \mathrm{UT}$ and reached its maximum negative value of $-187 \mathrm{nT}$ by $21 \mathrm{UT}$.

2-3 hours after the sudden changes of $B_{z} I M F$, at the main phase of geomagnetic storm, TEC increased within the area of the EIA up to 140-160 TECU in the noon-early afternoon sector, according to GIM (Fig.3 b, c). There also is a displacement of the EIA crests by about 5-10 ${ }^{\circ}$ of latitude from the geomagnetic equator (Fig. $3 \mathrm{~b}$ ).

The CHAMP satellite, passing near the dusk sector ( 19:30 LT), showed poleward displacement of the EIA crests by $\sim 10-15^{\circ}$ of latitude with concurrent TEC increases to 160 TECU above $\sim 400 \mathrm{~km}$. Apart from that, from CHAMP observations we can see a very large value of the ratio of TEC crest to the equatorial trough, which is the result of the penetration of the eastward electric field at middle and low latitudes that enhances the fountain effect (Vlasov et al., 2003). Note, that similar TEC changes are obvious from GIM data, so one can see good agreement between GIM data and satellite observations.

The TOPEX satellite passed over the Atlantic Ocean in the evening sector ( 18 LT) and recorded TEC levels of about 120-140 TECU below $\sim 1336 \mathrm{~km}$ in the EIA crests which were located at about $\pm 10^{\circ}$ magnetic latitude. In this longitude sector the ratio crest-to-trough of the EIA is close to normal and the location of the EIA crests is close to the usual position (Fig. $3 \mathrm{~b}, \mathrm{f}$ ). The TEC response in this longitudinal sector differs from that in the dusk sector (CHAMP observations). A similar effect was observed during the Bastille Day storm of July 2000 and was explained by different longitudinal conditions in the afternoon and evening sectors (Vlasov et al., 2003). The SAC-C data in the forenoon sector $(\sim 10: 30 \mathrm{LT})$ show a fourfold increase in TEC to $\sim 80$ TECU (Figs. 3a, 4a, $5 \mathrm{a}$ ) in the near-equatorial region (Fig. $3 \mathrm{~b}, \mathrm{f}$ ). By $22 \mathrm{UT}$, the TEC value in the dusk sector decreases to $\sim 130$ TECU and the ratio crest-to-through becomes close to normal (CHAMP TEC measurements, Fig. $3 \mathrm{c}$, g). The TEC above $\sim 715 \mathrm{~km}$ decreased to $\sim 40$ TECU. Unfortunately, the geometry of the TOPEX pass did not allow monitoring further TEC changes during the geomagnetic storm on 21-22 October 2001 (Fig. 3 c, g).

The subsequent sudden decrease of $\mathrm{B}_{\mathrm{z}}$ IMF down to $-15.4 \mathrm{nT}$ at 23 UT on 21 October 2001 caused recurring TEC enhancement up to 150-160 TECU below $1336 \mathrm{~km}$, up to 140-150 TECU above 400 km, and up to 50 TECU above $715 \mathrm{~km}$ (Fig. $3 \mathrm{~d}$, h). It should be noted that this time period does not correspond to the sudden drop of Dst but to the sudden drop of $B_{z}$ IMF, so significant TEC increase has strong dependence on $B_{z}$ variations..

Satellite measurements allowed us to measure TEC enhancements caused by the geomagnetic storm of 21-22 October 2001 in different longitudinal sectors from 10:30 LT to 19 LT. TEC enhancements in the afternoon sector correspond to a positive ionospheric disturbance produced by either a southward wind or an eastward electric field coupled with a small enhanced fountain effect. More significant TEC changes occurred in the dusk sector since at dusk the eastward penetration electric field may add to the eastward electric field because of the neutral dynamo (Basu et al., 2007).

\subsection{Storm of 7-8 September 2002}

The abrupt change of $\mathrm{B}_{\mathrm{z}}$ IMF to $-22 \mathrm{nT}$ at 17 UT on 7 September 2002 caused an intense geomagnetic storm and the following decrease of Dst to $-160 \mathrm{nT}$ at $18 \mathrm{UT}$. Further variations of $\mathrm{B}_{\mathrm{z}}$ at $22 \mathrm{UT}(-15 \mathrm{nT})$ lead to a subsequent Dst decrease down to $-187 \mathrm{nT}$ at $24 \mathrm{UT}$ (Fig. 2b). In this paper we will discuss TEC changes from 17 to 23 UT. 
As a response to the southward IMF $B_{z}$ event, the dayside near-noon TEC increased up to 140 TECU by 19 UT within the northern EIA crest, and up to 110 TECU within the southern crest (GIM data, Fig. 4b), i.e., the northern crest appeared to be more pronounced than the southern one. Similar north-south asymmetry was observed by the satellite altimeter Jason- 1 that passed near the local time $\sim 13$ LT and showed TEC maxima of 189 TECU (northern crest) and 154 TECU (southern crest). Concurrently, the crests moved to $\pm 21^{\circ}$ MLAT from their normal position, and the TEC over the equator was reduced, increasing the ratio of the equatorial crest-totrough TEC. All these observations are evidence of an enhanced fountain effect.

CHAMP passed near local time $15 \mathrm{LT}$ and detected that TEC above $400 \mathrm{~km}$ increased from 90 TECU (Fig. $4 \mathrm{a}, \mathrm{e}$ ) to $120 \mathrm{TECU}$, and two well pronounced peaks of the EIA were formed (Fig. 4 b, h). At the same time, according to SAC-C observations ( 10:30 LT), the TEC value above $715 \mathrm{~km}$ altitude increased to 60 TECU (Fig. 4 b, f), i.e., 2-2.5 times the value before the storm (Fig. 2 a, e).

From 21 UT the TEC value within the EIA crests started to decrease, and so did the ratio of crest-to-through TEC (Fig. 4c, g). However, the TEC value above $~ 400 \mathrm{~km}$ appeared to increase further to 170 TECU (northern anomaly) and to 140 TECU (southern anomaly). By 23 UT the crests of the EIA moved farther equatorward combining into a singular equatorial peak with a concurrent decrease of TEC value to 100 TECU (CHAMP and Jason-1 measurements, Fig. 4 d, h).

Thus, the satellite TEC measurements revealed large dayside TEC enhancements during the geomagnetic storm on 7-8 September 2002 in the forenoon-early afternoon sectors (from 10:30 LT to 15 LT). Dayside TEC increased after $\mathrm{B}_{\mathrm{z}}$ turned southward. At the main phase of the storm the two EIA crests appeared and further traveled poleward by $\sim 7^{\circ}$ of latitude. TEC above $\sim 400 \mathrm{~km}$ remained enhanced for about 5-6 hours after the southward IMF $B_{z}$ event started. The observed north-south asymmetry seems to be a result of the influence of neutral winds, since they are known to produce hemispheric asymmetry of the ionosphere with respect to the magnetic equator.

\subsection{Storm of 20-21 November 2003}

The sudden IMF negative $B_{z}$ increase to $-24 \mathrm{nT}$ at 12 UT on 20 November 2003 caused a sharp decrease in the Dst value down to $-229 \mathrm{nT}$ by 15 UT. Further steady decreasing of $\mathrm{B}_{\mathrm{z}}$ to a minimum value of $-51 \mathrm{nT}$ at $15-16$ UT provoked an extreme excursion of the Dst index to $-422 \mathrm{nT}$ by 20-21 UT (Fig. 2c). During the main phase of the geomagnetic storm TEC increased to 170-180 TECU with the EIA crests displaced poleward by about 5-10 of latitude from their regular position (from GIM, Fig.5 b, c).

CHAMP observed TEC enhancements to 140-150 TECU in the forenoon sector ( 11 LT). Both northern and southern crests of the anomaly are well pronounced (compared to the time of the storm initial phase, Fig. 5 a, e) and have their maximums at $\sim 20^{\circ}$ MLT. TEC measurements performed by TOPEX showed no less than 100 TECU around the evening sector ( 19 UT, Fig. 5 b, f). TEC within the southern crest of the EIA reached $~ 150$ TECU by 20-21 UT (Fig. 5 c, g). The SAC-C pass occurred close to $~ 10: 30$ LT and recorded TEC increases of up to 60 TECU for altitudes above $715 \mathrm{~km}$. This effect of the ionosphere uplift lasted for 2-4 hours (Fig. 5c, g), in response to the long-term impact of the negative $B_{z} I M F$.

For these times one can notice a substantial error in the estimation of vertical TEC in GIM: according to the simultaneous satellite observations, the storm-enhanced TEC area was much more elongated along the geomagnetic equator, from the forenoon to the dusk sector (Fig.5 b, c). Starting at 24 UT, $\mathrm{B}_{\mathrm{z}}$ turns northward (Fig. 2c) and the CHAMP and TOPEX measurements show only a single equatorial peak (Fig.5 d, h). The dayside TEC level did not exceed 80-90 TECU, i.e., it stayed close to the "quiet-time” TEC level, although the Dst level was still extremely low (-309 nT).

The dayside ionospheric uplift seems to have a strong dependence on IMF $\mathrm{B}_{\mathrm{z}}$ variations. From Fig. 3-5 one can see that even when the character of TEC changes due to geomagnetic storms is similar, TEC values for $\mathrm{h}>715$ $\mathrm{km}$ may be different. During the geomagnetic storm of 20 November 2003 TEC remained significantly enhanced for more than 3-4 hours, whereas for the storms of October 2001 and September 2002 the SFE lasted for 1-2 hours. Apparently, this was caused by the fact that $B_{z}$ IMF had values less than $-25 \mathrm{nT}$ for more than 8 hours, reaching the extreme value of $-51 \mathrm{nT}$ at 15-16 UT on 20 November 2003. TEC returns to its "quiet-time" level after $B_{z}$ turns northward (Figs. 4d, 5d). 
Unfortunately, the geometry of the SAC-C passes did not allow us to see the ionosphere uplift above $715 \mathrm{~km}$ during the storm on 7 November 2004. However, we derived analogous results from CHAMP and Jason-1 TEC measurements for this event: at the main phase of the geomagnetic storm the EIA crests moved poleward and the equatorial TEC value increased, and the ratio crest-to-trough TEC went up. All these effects appear to be strong evidences of the SFE (Vlasov et al., 2003; Mannucci et al., 2005; Basu et al., 2007).

\section{Conclusions and discussions}

Simultaneous use of data of satellite altimeters TOPEX and Jason-1, and measurements from GPS-receivers onboard CHAMP and SAC-C satellites allowed us to assess the dayside redistribution of ionospheric plasma during intense geomagnetic storms. Since the satellites passed over different longitudinal sectors and measured TEC in different range of altitudes we could obtain information about altitude and longitudinal ionosphere effects. The principal results from the investigation areas follows:

1. During strong geomagnetic storms on 21-22 October 2001, 7-8 September 2002, and 20-21 November 2003 we observed extreme TEC enhancements in the equatorial region (up to 50\%) with concurrent poleward traveling of the EIA crests for a distance of $5-15^{\circ}$ of latitude. At the same time, TEC above $715 \mathrm{~km}$ increased to 2-3 times the quiet-time TEC level. Such phenomenon, known as the daytime "super-fountain" effect, occurred after sudden decreases in IMF $B_{z}$ and consequent penetration of electric fields to the low-latitude ionosphere. The SFE weakened after the $B_{z}$ value increased and turned northward. Our results on the SFE are in good agreement with previous observations (Vlasov et al., 2003; Tsurutani et al., 2004, 2008; Mannucci et al., 2005; Basu et al., 2007).

2. Significant dayside TEC changes seem to have strong dependence on IMF $B_{z}$ variations. From Fig. 3-5 one can see that even if the character of TEC changes due to geomagnetic storms is similar, TEC above $\sim 715 \mathrm{~km}$ on 20 November 2003 remained severely enhanced much longer than during the storms of October 2001 and of September 2002. Apparently, this effect was caused by the fact that $B_{z}$ IMF remained below $-25 \mathrm{nT}$ for more than 8 hours, reaching the extreme value of $-51 \mathrm{nT}$ at $15-16 \mathrm{UT}$.

3. In general, GIM show a good agreement with satellite observations: the maps reflect very well the dynamics of the TEC redistribution during geomagnetic storms. However, at equatorial latitudes noticeable differences in the VTEC values estimated by GIM and those measured by the satellites were observed times (e.g., Fig. 5).

\section{Acknowledgements}

The author is grateful to Prof. Edward Afraimovich (ISTP SB RAS) for his interest to this work, to Dr. Pavel Tatarinov (ISTP SB RAS) for his help in data processing, to Dr. Kirill Palamartchouk (University of Oxford, Department of Earth Sciences) and the Technical University of Crete for their help with data of satellite altimeters TOPEX and Jason-1, and to the two reviewers for their useful comments and suggestions. We acknowledge Potsdam Geophysical observatory GFZ for CHAMP data, NASA Goddard Space Flight Center for SAC-C data, CNES and NASA for data of satellite altimeters TOPEX and Jason-1, and the Jet Propulsion Laboratory of California Institute of Technology (JPL) and the Center for Orbit Determination in Europe, University of Berne, Switzerland (CODE) for GIM.

The research is supported by the Japan Society for the Promotion in Science (JSPS).

\section{Reference}

Abdu, M.A., G. O. Walker, G, B. M. Reddy, J. H. A. Sobral, B. G. Fejer, T. Kikuchi, N. B. Trivedi, and E. P. Szuszczewicz, Electric field versus neutral wind control of the equatorial anomaly under quiet and disturbed conditions: A global perspective from SUNDIAL-86, Ann. Geophysicae. 8, 419-430, 1990.

Abdu, M.A., Sobral, J.H.A., de Paula, E.R., Batista, I.S. Magnetospheric disturbance effects on the Equatorial Ionization Anomaly: an overview. J. Atm. Terr. Phys. 53, N8, 757-771, 1991. 
Afraimovich E.L., S.V. Voeykov, P.V. Tatarinov. Experimental evidence of the solitary internal gravity wave existence during the major magnetic storm on October 30, 2003, as deduced from data of global GPS network and GPS receiver on the LEO satellite CHAMP. Proceedings of URSI GA 2005, GP1.16(0245).

Astafyeva E.I., Afraimovich E.L., Kosogorov E.A. Dynamics of total electron content distribution during strong geomagnetic storms. Adv. Space Res. 39, 1313-1317, DOI:10.1016/j.asr.2007.03.006, 2007.

Balan, N., Bailey, G.J. Equatorial plasma fountain and its effect: Possibility of an additional layer, J. Geophys. Res., Vol. 100, A11, 21421-21432, 1995.

Basu, S., Basu, Su., Rich, F.J., Groves, K.M., MacKenzie, E., Coker, C., Sahai, Y., Fagundes, P.R. and BeckerGuedes, F. Response of the equatorial ionosphere at dusk to penetration electric fields during intense magnetic storms. J. Geophys. Res, 12, A08308, doi:10.1029/2006JA012192, 2007.

Bilitza, D., Koblinsky, C., Zia, C., Williamson, R., Beckley, B. The equator anomaly region as seen by the TOPEX/POSEIDON satellite. Adv. Space Res. 18, 623-632, 1996.

Fejer, B.G. Low latitude electrodynamic plasma drifts: a review. J. Atm. Terr. Phys., Vol. 53, N8, 677-693. 1991.

Foster, J.C and Rideout, W. Midlatitude TEC enhancements during the October 2003 superstorm. Geophys. Res. Letters. 32, 12, DOI 10.29/2004GL02719, 2005.

Fu, L.L., Christensen, E.J., Yamarone, C.A. Jr., Lefebvre, M., Menard, Y., Dorrer, M. and Escuder, P. TOPEX/Poseidon mission overview. J. Geophys. Res., 99, 24396-24381, 1994.

Gonzalez, W. D., Joselyn, J. A., Kamide, Y., Kroehl, H. W., Rostoker, G., Tsurutani, B. T., Vasyliunas, V. M. What is a geomagnetic storm? J. Geophys. Res., Vol. 99, A4, 5771-5792, 1994.

Gonzalez, W.D. and Tsurutani, B.T. Criteria of interplanetary parameters causing intense magnetic storms $\left(\mathrm{D}_{\mathrm{st}}<\right.$ -100 nT), Planetary and Space Science, Volume 35, Issue 9, p. 1101-1109, 1987.

Huang, C., Foster, J., Kelley M.C., Long-duration penetration of the interplanetary electric field to the lowlatitude ionosphere during the main phase of magnetic storms. J. Geophys. Res., 110, A11309, doi:10.1029/2005JA011202, 2005.

Mannucci, A.J., Wilson, B.D., Yuan, D.N., Ho, C.M., Lindqwister, U.J. and Runge, T.F. A global mapping technique for GPS-drived ionospheric TEC measurements. Radio Science 33, 565-582, 1998.

Mannucci, A.J., Tsurutani, B.T., Iijima, B.A., Komjathy, A, Saito, A., Gonzalez, W.D., Guarnieri, F.L., Kozyra, J.U. and Skoug, R. Dayside global ionospheric response to the major interplanetary events of October 2930, 2003 “Halloween Storms”. Geophys. Res. Letters. 32, 12, DOI 10.29/2004GL021467, 2005.

Schaer, S., Beutler, G., Rothacher, M. Mapping and predicting the ionosphere. Proceedings of the IGS AC Workshop, Darmstadt, Germany, February 9-11, 307-320, 1998.

Tsurutani, B., Mannucci A., Iijima, B., Abdu, M.A., Sobral, J.H.A., Gonzalez, W., Guarneri, F., Tsuda, T. et al. Global dayside ionospheric uplift and enhancement associated with interplanetary electric fields. J. Geophys. Res. 109, A08302, 2004.

Tsurutani, B.T., Verkhoglyadova, O.P., Mannucci, A.J., Araki, T., Sato, A., Tsuda, T., and Yumoto, K. Oxygen ion uplift and satellite drag effects during the 30 October 2003 daytime superfountain event, Ann. Geophys., 25, 569-574, 2007.

Tsurutani, B.T., Verkhoglyadova, O.P., Mannucci, A.J., Saito, A., Araki, T., Yumoto, K., Tsuda, T., Abdu, M.A., Sobral, J.H.A., Gonzalez, W.D., McCreadie, H., Lakhina, G.S. and Vasyliunas, V.M., Prompt 
penetration electric fields (PPEFs) and their ionospheric effects during the great magnetic storm of 30-31 October 2003 , J. Geophys. Res., 113, A05311, doi:10.1029/2007JA012879, 2008.

Vlasov, M., M.C. Kelley, H. Kil, Analysis of ground-based and satellite observations of F-region behavior during the great magnetic storm of July, 2000, J. Atm. Sol.-Terr. Phys., 65, 1223-1234, 2003.

Zhao, B., Wan, W., Liu, L. Responses of equatorial anomaly to the October-November 2003 superstorms. Ann. Geophys. 23, 693-706, 2005. 


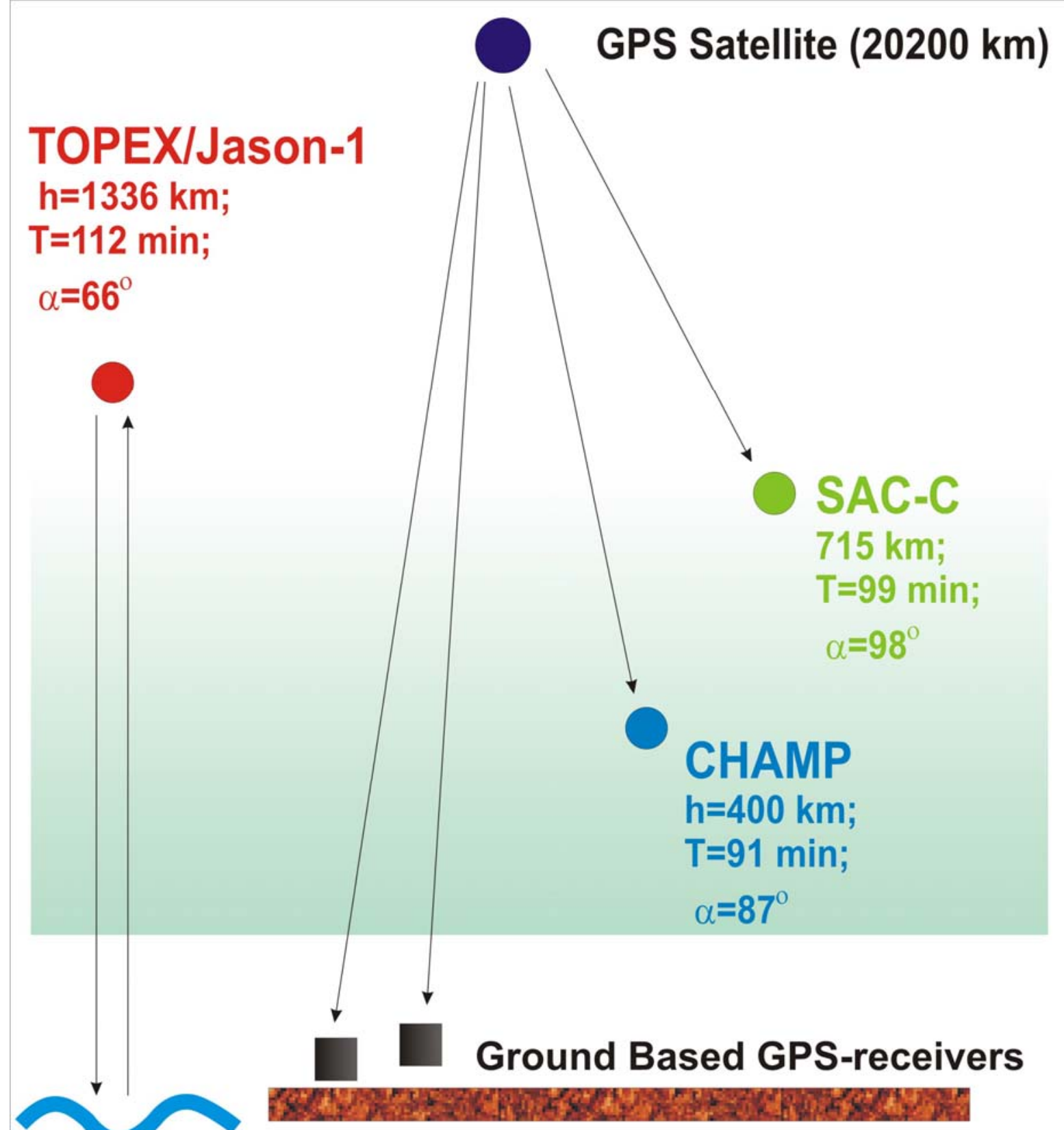

Figure 1. A scheme of ionosphere observations performed by GPS receivers on-board CHAMP and SAC-C satellites and by altimeters carried by the TOPEX and Jason-1 satellites. The satellites orbital parameters are indicated on the panel. 


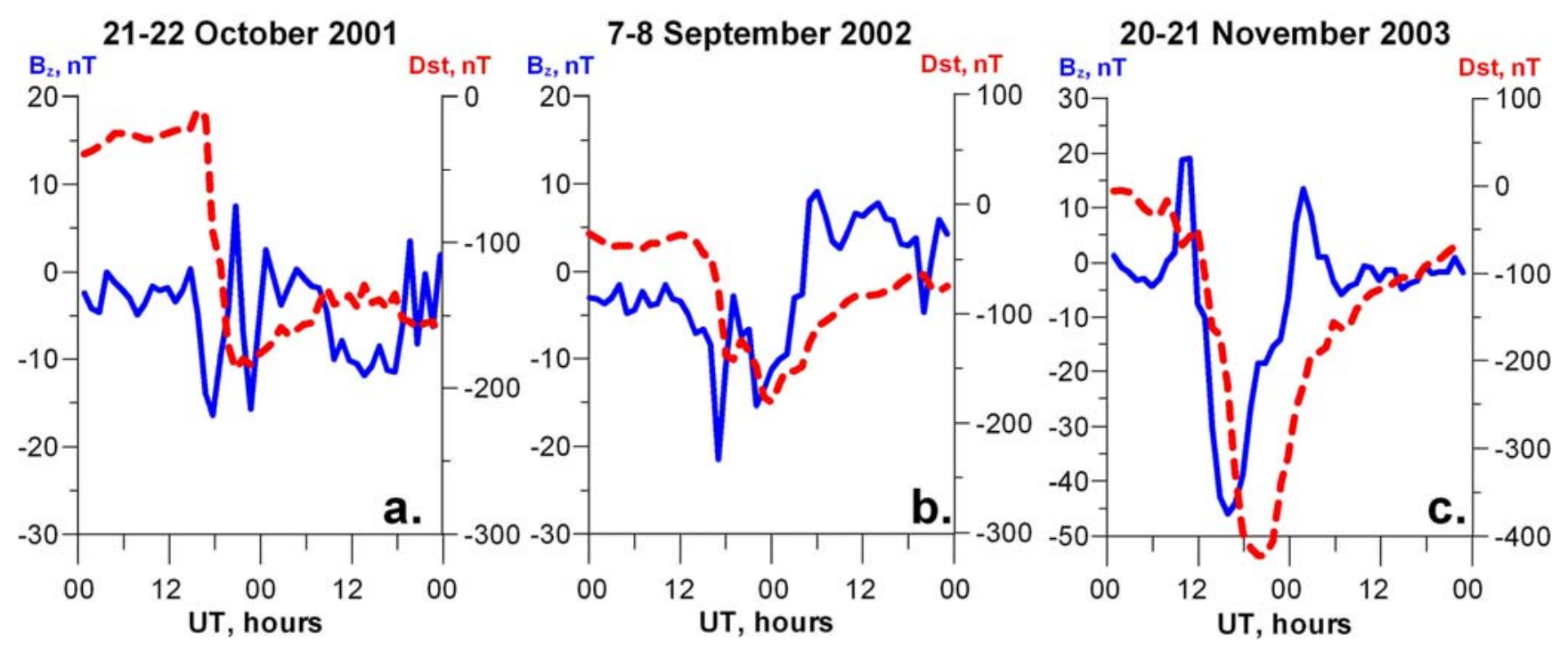

Figure 2. Variations of $B_{z}$ component of the IMF (blue continuous curves) and of index of geomagnetic activity Dst (red dotted curves). 


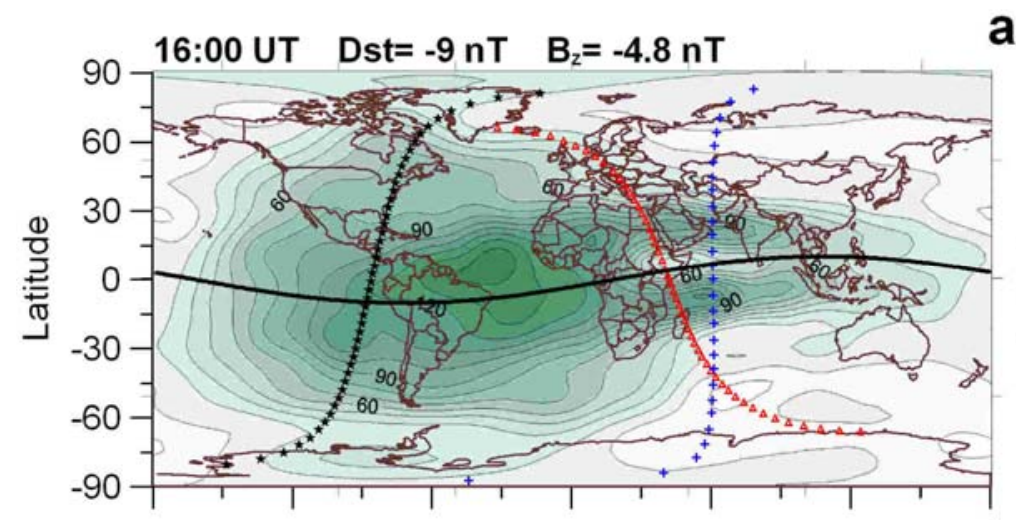

a.
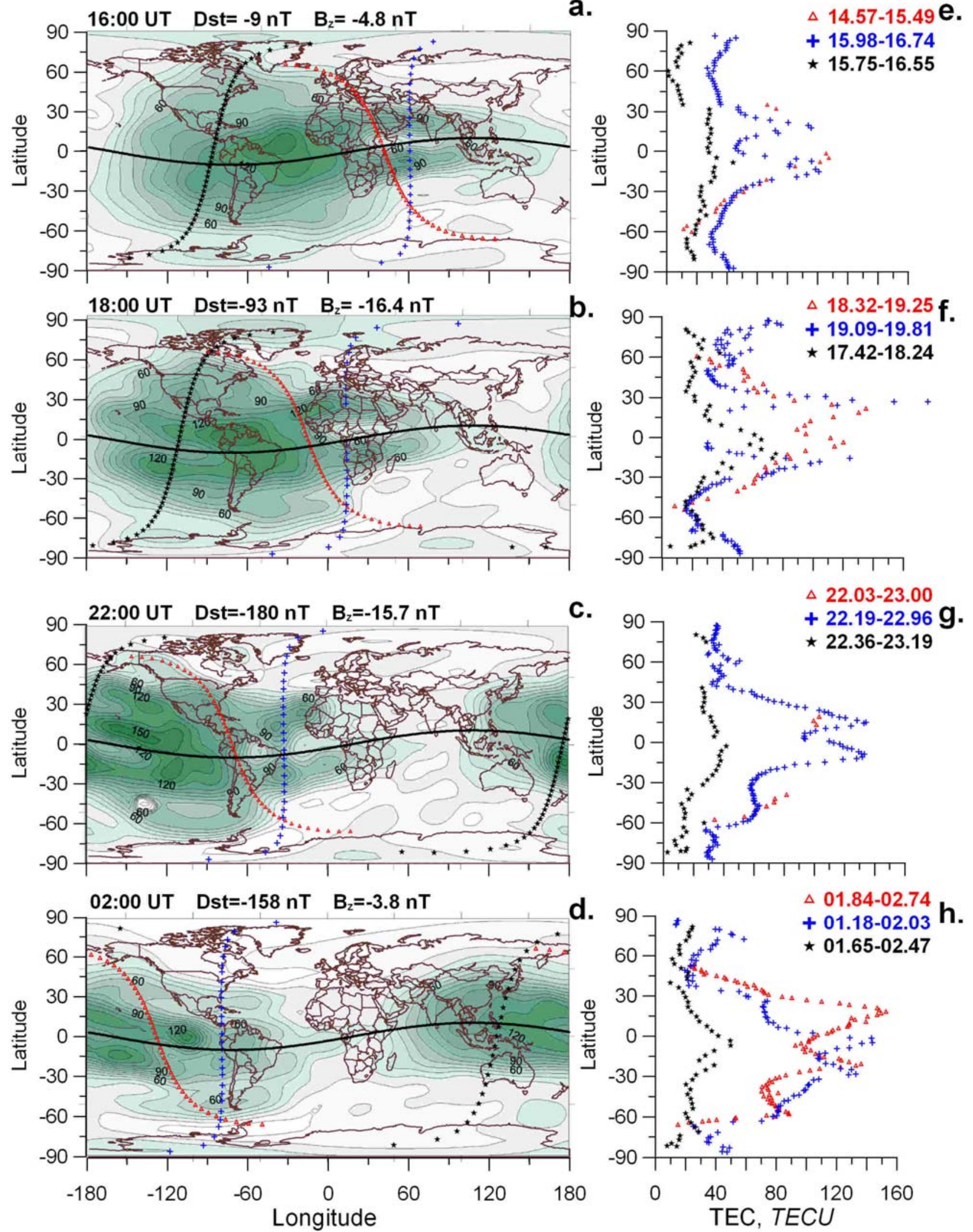

Figure 3. TEC changes during the geomagnetic storm on 21-22 October 2001 (from 16 UT on 21 October to 02 UT on 22 October). Maps of vertical TEC (GIM results) are presented in panels (a-d), TEC isolines are indicated by thin black lines, numbers show TEC values in TECU. TEC measurements performed by TOPEX (below $1336 \mathrm{~km}$, triangles), CHAMP (above $350 \mathrm{~km}$, crosses) and SAC-C satellites (above $715 \mathrm{~km}$, stars) are shown on panels e-h. The trajectories of the satellites are indicated on panels (a-d) in triangles, crosses, and stars, respectively. UT of the satellites flights is written on panels $\mathbf{e - h}$. Dst and $\mathrm{B}_{\mathrm{z}}$ values for $16,18,22$, and 02 UT are given on panels a-d. 


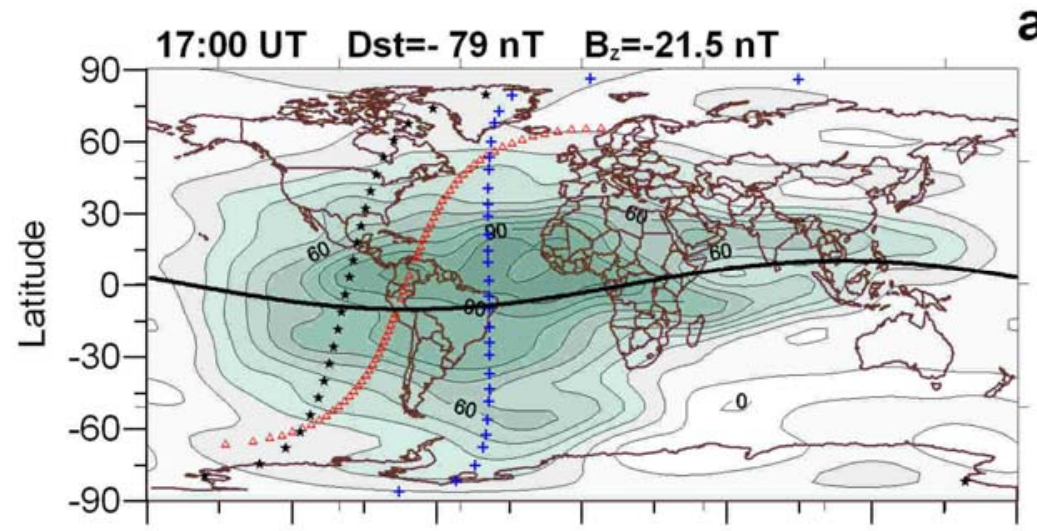

a.

e.
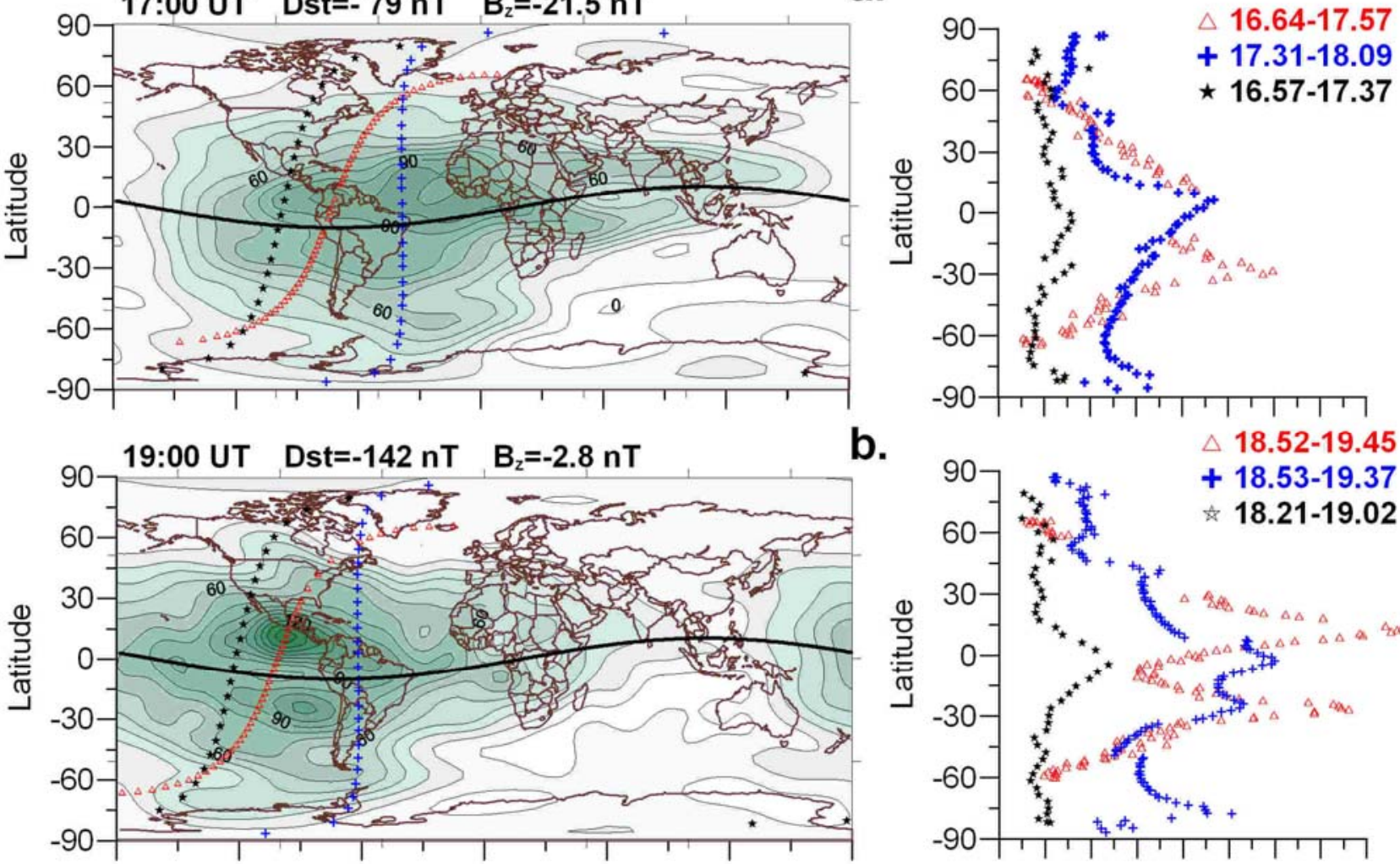

b.
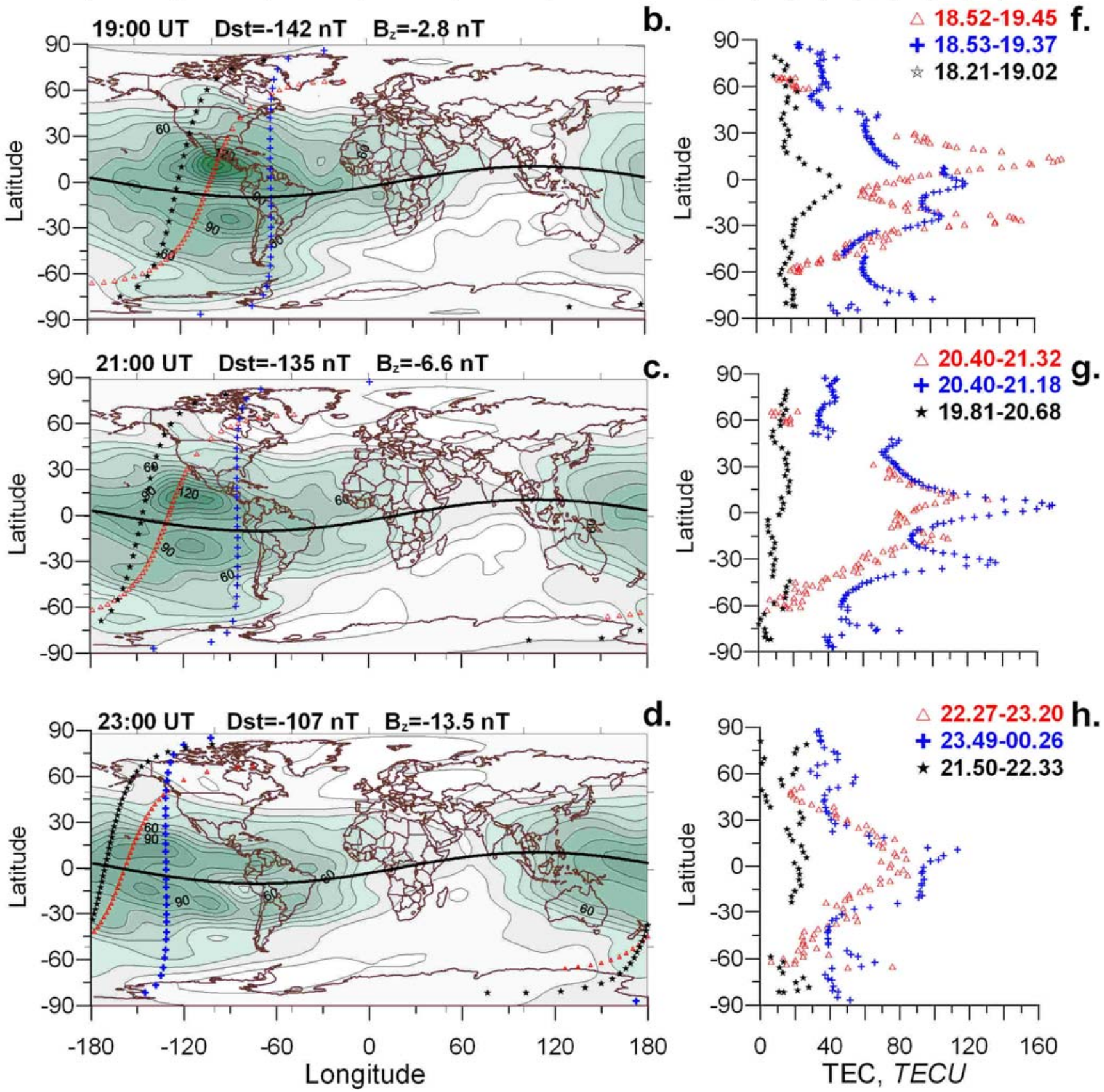

Figure 4. The same as in Figure 3 but for the geomagnetic storm on 7 September 2002 and Jason-1 measurements (triangles), from 17:00 to 23:00 UT. 

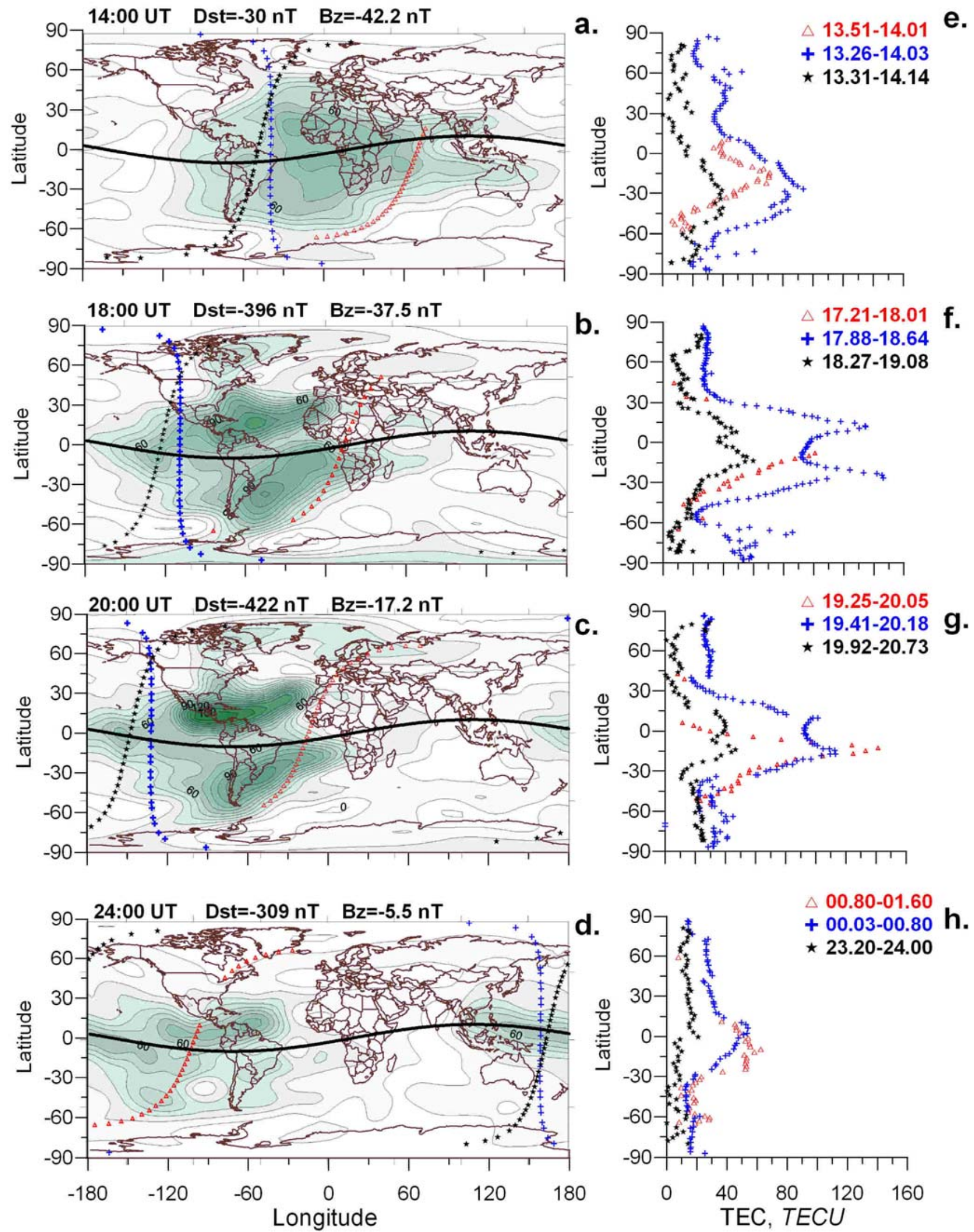

Figure 5. The same as in Figure 3 but for the geomagnetic storm on 20 November 2003, from 14:00 to 24:00 UT. 